\title{
Training of High-qualified and Application-oriented Talents Should Have Distinct Industrial Characteristics
}

\author{
Hong Gan ${ }^{1}$ and Yizhen Yang ${ }^{2 a}$ \\ ${ }^{12}$ College of Civil Engineering and Architecture, Anhui Polytechnic University \\ ayyiz2006@163.com
}

Keywords: applied talents, talent training quality, cooperation by production, study and research

\begin{abstract}
Facing the industry and train high quality applied talents, this is one of the important transformation of higher education in China. In fact, since 2008, began to explore the transformation of the local undergraduate universities in our province, established the applied undergraduate colleges and universities alliance, clearly put forward the collective transformation, the means of development, the resources sharing. Anhui Polytechnic University also explicitly proposed the high-quality applied talents training goal. Why transformation in local colleges, some scholars from the perspective of higher education reform "two 30 years" the reflection, believe that after thirty years of education reform, adhere to the "three facing", is actually for 30 years before the "combining education with productive labor" education idea of major innovations. We believe that this kind of reflection to the transformation of the local colleges and universities are ongoing, undoubtedly have important reference.
\end{abstract}

\section{The necessity of cultivating high-quality practical engineering talents}

With the progress of technology and the rapid development of economy and society, the new technology revolution represented by information science, biotechnology and energy technology, leads to the big changes of industrial structure, economic structure and social structure. The pattern of social culture diversity, economic structure diversity, and talented person demand diversity has been basically formed. Different region and different industry have different demand for talents, and higher education are facing with ever more complex, rich and diverse persons. Since the 2011 "outline of national medium and long-term program for education reform and development" was published, our country has made the strategy to build an innovation-oriented country, and explicitly proposed to "establishing the enterprise as the subject, market oriented, the combination of technology innovation system, guidance and support to the enterprise cluster innovation elements, promoting the transformation of scientific and technological achievements into realistic productivity." Quality view of colleges and universities also be profound changes accordingly. In the next 10 years, the core mission and the most distinctive feature of higher education reform is improving quality. The core of improving quality must set up the correct education quality view and train high-quality practical talents for social needs.

Because now the social demand for talents shows the situation of multiple specifications, multi-type and multi-level, the position and role of higher education has been greatly changed .Higher education not only cultivates scholars, scientists and political leaders, such as "elite" minority, but also faces the society from all walks of life and cultivates applied senior specialized talents, which brings new opportunities and severe challenges for the development of higher education. At the same time, in the knowledge economy society, the update of knowledge is further speeding up, the new jobs are created, and no school or profession can cultivate all-rounder. So the demand for talents tends to mastering many skills while specializing in paretic.

Visible, cultivating applied talents is the higher education from elite education to mass education stage of development inevitable product, and is the inevitable requirement of economic and social 
development. Second, we cultivate application -oriented engineering should have a kind of learning and skills, engineering and technology mix of compound, unlike the former, the outstanding characteristics of "application" at the same time, also should have the characteristics of the "comprehensive quality and harmonious development". Third, the most prominent feature is the ability of the high-quality practical talents of systematic instead of systemic knowledge training, and jobs and career oriented, compared to cultivate skilled applied talents of high quality applied talents for the industry, it requires students to have a more comprehensive professional knowledge and good cultural quality, stronger ability of sustainable development.

Applied talent is a kind of learning and skills, the combination of engineering and technology talents. We advocate the high quality applied talents, it is now an innovative social diversification demand, it is difficult to the knowledge, skills, simple compound can be meet. For high quality applied talents in the outstanding characteristics of "application" at the same time, also has the characteristics of "comprehensive quality, coordinated development". Embarks from the social demand, should with "good enough" and "utility" in the limit requirements gradually changes from a solid ", enhance the staying power ".In terms of ability, have strong technical application ability, good at discovering and problem solving skills, also has strong innovation consciousness and innovation ability. In terms of quality, decision-making and solve actual problems not only needs scientific and technological factors, at the same time, you have to consider social factors such as politics, economy and management, as well as the strong ability of social adaptation and so on. High quality applied talents should not only have higher professional qualities and professional skills, but also have higher ideological and political, humanities, such as professional quality professional accomplishment. That is what we emphasize the cause of the high-quality practical talents training.

\section{The View of High-quality practical talents cultivation}

Applied talents is relative to the case of academic talents, is a qualified for a line of production and have corresponding values, view of engineering, engineering intelligence and outstanding engineering practice ability of senior engineering and technical personnel and management personnel. Modernization of experience from developed countries, the economic and social development of talent demand eventually present a "featured" trend, namely academic talent of minority, a large number of applied talents with specialized knowledge and skills. Especially the progress of the current our country industrialization construction, the development of high and new technology, speed up the strategic adjustment of economic structure in China, the high and new technology industry is quickly to replace the traditional industries, to speed up the production shift from labor-intensive to high-tech knowledge. This not only requires a lot of skilled workers and ordinary technical management personnel, more can need a lot of in the production, engineering, management, management, etc. The first line is engaged in the applied research, technology development, trial production, can make the research work to deepen, the production level of senior engineering and technical personnel and advanced production and management personnel, high-quality practical talents cultivation quality standards.

The characteristics of high-quality talent has three aspects: good humanities accomplishment, such as the ideal faith, respect, love, understanding, care, tolerance, fair and justice, etc.;Have good professional ethics, such as her, bears hardships and stands hard work, meticulous, law-abiding, abide by credit, etc; With strong social ability, communication ability, organization and management ability, such as communication unity cooperation ability, language ability, the basic theory of computer, foreign language, professional knowledge and basic skills, professional body, etc. Should be high comprehensive quality of the high-quality practical talents, the basis of basic theory knowledge, with system of professional practice skills training, can will learn professional knowledge and skills to use in production, construction, management, service post, is engaged in the planning, design, management, operation and so on a work of specialized personnel. 
The quality standard is designed for the development of the national modernization and innovative society. The popularization of higher education, promoted the transformation of higher education demand function, higher education is not only meet the demand of national culture scholars, scientists and political leaders, such as "elite" minority, but faces the society from all walks of life, adapt to and lead the social development and application. The scientific development is the social from all walks of life, to gather the torrent of the national modernization development. Therefore, facing the industry fostering applied talents, professional type, special requirements from all walks of life to meet growing society, countries should be the fundamental task of higher education. Our undergraduate education should enable students not only to master the disciplines and specialties and systematically the necessary basic theory, basic knowledge, grasp the basic skills needed in the area, the method and the related knowledge, have engaged in this specialized practical work and research work of the preliminary ability, should also have high comprehensive quality and solid professional knowledge and applied knowledge, and can solve the problem of theory was applied to the actual, senior specialized talents with outstanding application ability. Only a high standard, high quality, it is this quality, is the modern technology, users and implementers.

\section{Training the high-quality practical talents for the industry}

Training the high-quality practical talents for the industry includes two aspects: One is to define cultivating what kind of talents; and the second is to clear the basic specification and quality of this kind of talent. The starting point of the high-quality practical talents training goal is a new trend which is according to the requirement of regional economic and social development. On the one hand, the improvement of the professional knowledge and the technical content is promoted by the scientific and technological progress; On the other hand, economic and social development and the progress of science and technology has given rise to new jobs, especially complex jobs, lead to demand for high-quality talents spurt.

Our goal is the training the high-quality practical talents who can meet the needs of economic and social development, and to be able to do in the production, engineering, management, service the first line. The criteria of training about the knowledge, ability and quality are still to define the three elements. But the connotation of the three elements are different: theoretical base of the applied discipline is more solid, and it should not be ignored that the recessive knowledge is constituted by the knowledge of experience and working process; The quality of professional ethics and professional quality to develop more outstanding; The two training of application ability and key ability are equally important.

The processes of talent training and social needs should be docking, this is the important content of personnel training for industry under the background of cooperation by production, study and research. Production-study-research cooperation is the inevitable requirement for the college talent training, research and development of Science and technology, and social services.

Adhere to the unity of the school has become a characteristic of facing the industry and strategy. Practice also proved that the integration teaching university-industry cooperation in supporting industry development, the student consciousness of industry and professional quality plays a decisive role. As an innovative country strategy is put forward, has the innovation system of region and industry characteristics is becoming more and more concern and attention, colleges and universities in national innovation system, the important position and role of emerging culture oriented industry first-line application-oriented and innovative talents are imperative.

But, at present, we also have some departments that are insufficient in industry and some students that are uneven in social adaptation ability. We consider it is desirable and encouraged that professional departments can run its education and teaching for corresponding industry. Profession should be considered of a specialized business in specific industries, while teaching, we can introduce 
professional connotation, professional knowledge, professional skills and relevant professional skills test. What's more, major industries with intensive capital, intensive technology and human resource have technology innovation subject advantages. If technology innovation could not be occupied by school, it is dangerous for school to be ignored by industry. If school wants to maintain and strengthen the dominant position in the field of industry, it must strengthen interior building, have university-industry cooperation advantages into full play, continue to expand the depth and breadth of university-industry cooperation.

\section{Quality education should focus on the characteristics of the practice itself}

According to guiding principle for education, in the higher education we should train the professional socialism talents who have all-round attainments in moral, intellectual, physical and aesthetic education, with the combination of humanity quality and scientific quality and with innovative spirit and practice ability. About the high-quality practical talents training goal, one is to define cultivating what kind of talents; and the second is to establish clear basic specification and quality of this kind of talent. The high-quality practical talents training goal in the industry, first, according to industry needs, training professional people who can meet the needs of economic and social development, do well job in production, engineering, management and can service forefront is needed. Training standards can also set up on the basis of Knowledge, ability and quality, but it is more outstanding with more solid in applied science theories. With empirical knowledge and working process of the knowledge accumulated, including the outstanding aspects of quality of professional ethics and professional quality. Its outstanding performances are reflected in practical ability, well basic knowledge, strong learning ability, ability to adapt quickly, and have certain innovation quality. Training high-quality practical talents also lay a solid foundation for students in humanism sentiments.

Finally, practice is very important in all the teaching in education. Over the years, the majority of teachers in the teaching reform will naturally focus on reforms related to practice. However, it has to say, that a lot of knowledge about the practical aspects of the project still remain in terms of the level on the matter. At best, the practice is as the important part of cultivating the ability of innovation. If the practice aspects of engineering education play a bigger role as much as possible, we need to know practice from a deeper level. In face to the practice aspects of the industry, in the first of all and the most highlight is the following points. (1) Subjective consciousness for the industry: We should pay attention to help students to exert initiative and creativity, to allow students to imagine, and to allow students to practice. Especially it needs to be emphasized is that the students' subjective consciousness in professional positions in the future, will be able to exert the principal responsibility of jobs; (2) Normal consciousness for long-term: This job if not for life, but at least should also be long-term, so the normal consciousness of the practice: is more important; (3) Society consciousness of the practice: Engineering practice is not entirely in the enterprise or the engineering training center in campus, should also be in society, especially engineering practice in the industry should be like this; (4) space imagination consciousness: It is not hard to imagine the development of the information society in the virtual reality technology in the future. Students can use it to complete some practical activities, especially the practice of cognitive, and this can further expand our imagination and innovation space.

We consider that we can certainly train the high-quality practical engineering talents welcomed by the society, as well as we do it for the industry, emphasizing the students' subjective consciousness and long-term training. In recent years, our university civil engineering professional training scheme, adhere to the production, the depth of the fusion, adhere to the direction of the cultivation of applied talents, in the cultivation of the students application ability has made great progress, students' employment has been at the top of each professional, double gen graduates welcomed by society. 


\section{Acknowledgements}

This work was financially supported by National social science fund project (BIA110076) and Anhui Provincial key research projects (2012jyxm272) and College students' innovative entrepreneurial training project in Anhui Province"The detection, identification and reinforcement application research of structures".

\section{References}

[1]Gan Hong, Xu Daqi. On the Training of High-qualified and Application-oriented Talents of Engineering[J], Research in Higher Education of Engineering, 2010,(6):44 - 48

[2]Gan Hong, Xu Daqi, Ran Kunyu. Enhancing Capacity Building to nurture high-quality practical talents[J], Journal of national academy of education administration, 2010, (10): 52-55

[3]Gan Hong, Xu Daqi. Renew quality view, Training high-quality practical talents[J], China High education, 2011, (3/4): 52-54.

[4]Gan hong, Lv zhiyong. Application and their economic analysis of the base isolation technology[J].Journal of AnHui Polytechnic University,2013.6

[5]Gan hong, Yang yizhen. Nonlinear dynamic analysis of the damping frame structure system. Advanced Materials Research,2012.8 